\title{
The emerging role of CaMKII in cancer
}

\author{
Yan-yang Wang ${ }^{1,2}$, Ren Zhao ${ }^{1,2}$ and Hong Zhe ${ }^{1,2}$ \\ ${ }^{1}$ Department of Radiation Oncology, General Hospital of Ningxia Medical University, Yinchuan, Ningxia, China \\ ${ }^{2}$ Cancer Institute, Ningxia Medical University, Yinchuan, Ningxia, China \\ Correspondence to: Hong Zhe, email: nxzh1961@hotmail.com \\ Keywords: Ca2+/calmodulin-dependent protein kinase II (CaMKII), cancer, cell cycle, therapeutic target, CaMKII inhibitor \\ Received: January 10, 2015 \\ Accepted: April 08, 2015 \\ Published: April 29, 2015
}

This is an open-access article distributed under the terms of the Creative Commons Attribution License, which permits unrestricted use, distribution, and reproduction in any medium, provided the original author and source are credited.

\section{ABSTRACT}

$\mathrm{Ca2+/calmodulin-dependent} \mathrm{protein} \mathrm{kinase} \mathrm{II} \mathrm{(CaMKII)} \mathrm{is} \mathrm{a} \mathrm{multifunctional}$ serine/threonine kinases best known for its critical role in learning and memory. Recent studies suggested that high levels of CaMKII also expressed in variety of malignant diseases. In this review, we focus on the structure and biology properties of CaMKII, including the role of CaMKII in the regulation of cancer progression and therapy response. We also describe the role of CaMKII in the diagnosis of different kinds of cancer and recent progress in the development of CaMKII inhibitors. These data establishes CaMKII as a novel target whose modulation presents new opportunities for cancer diagnosis and treatment.

\section{INTRODUCTION}

Calcium ion $(\mathrm{Ca} 2+)$ is a ubiquitous intracellular signal responsible for a broad range of cellular events, such as cell growth, cytoskeletal organization, regulation of synaptic transmission, and $\mathrm{Ca} 2+$ homeostasis[1-3]. The $\mathrm{Ca} 2+/$ calmodulin $(\mathrm{CaM})$-dependent protein kinases (CaMKs) are multifunctional serine/threonine kinases whose activity are regulated through $\mathrm{Ca} 2+$ signaling [4]. Recent studies demonstrated that high levels of different isoform of CaMK, especially for CaMKII, expressed in several cancers such as lung [5], breast [6], prostate [7] and colon cancer [8]. CaMKII phosphorylates nearly 40 different proteins, including enzymes, ion channels, kinases, and transcription factors $[9,10]$ and plays a critical role in the regulation of proliferation, differentiation and survival of various cancer cells [5-8]. In this review, we will focus on the structure and biology properties of CaMKII, including the roles of CaMKII in the regulation of cancer proliferation and therapy response. The role of CaMKII as a biomarker in cancer diagnosis and the application of CaMKII inhibitors in cancer research will also be discussed in this review.

\section{STRUCTURE AND ACTIVATION OF CAMKII}

CaMKII is expressed as a multimeric protein, which typically comprised of 12 subunits in most commonly observed physiological conditions [11]. Each of these subunits has an N-terminus catalytic domain, followed by a regulatory domain, and a C-terminus association domain responsible for multimerization (Figure 1). Like other kinases, the catalytic domain of CaMKII has an ATP-binding pocket that creates a microenvironment to lower the energy required to hydrolyze ATP, enhancing the rate of transfer for the $\gamma$ phosphate from ATP to a target $\mathrm{S} / \mathrm{T}$ and ejecting ADP [12]. The regulatory domain of CaMKII has a C-terminus $\mathrm{Ca} 2+/ \mathrm{CaM}$ binding region and an N-terminus autoinhibitory region [13]. The autoinhibitory region contains most of the elements that are critical for regulation of CaMKII activity, including the post translational modification (PTM) segment for phosphorylation, O-linked $\mathrm{N}$-acetylglucosamine (O-GlcNAC) modification, and oxidation $[9,14]$.

There are four different CaMKII genes, and each gene encodes a distinct CaMKII isoform $(\beta, \gamma$, and $\delta$ ). All CaMKII isoforms appear to share common regulatory mechanisms and protein targets but differ in tissue distribution [15]. Under resting conditions, the catalytic domain is constrained by the autoinhibitory sequences on the regulatory domain, thereby inhibiting the activity of the enzyme [12]. When intracellular $\mathrm{Ca} 2+-$ levels periodically rise during the cellular $\mathrm{Ca} 2+-$ transient, $\mathrm{Ca} 2+$ binds to $\mathrm{CaM}$ and activates CaMKII by binding to the regulatory domain. The activation leads to the phosphorylation of adjacent CaMKII subunits at 
Thr286 (for the $\alpha$ isoform) or at Thr287 ( for the $\beta, \gamma$, and $\delta$ isoforms). The phosphorylation of Thr287 has at least two effects on CaMKII. The binding affinity of CaM for the CaMKII regulatory domain increases by more than 1000-fold. Additionally, the negatively charged phosphate group at the Thr287 site precludes reassociation of the catalytic and regulatory domains, preventing autoinhibion even if $\mathrm{Ca} 2+$ falls and $\mathrm{CaM}$ dissociates from CaMKII . The autonomous activation of CaMKII by Thr287 phosphorylation will persist until the phosphate group is removed by a protein phosphatase $[10,16,17]$.

Elevated reactive oxygen species (ROS) level upregulates CaMKII through direct and indirect ways. The regulatory domain of CaMKII contains a pair of redoxsensitive amino acids (Cys280/Met281 in the $\alpha$ isoform, Met281/Met282 in the $\beta, \gamma$, and $\delta$ isoforms) that can be oxidized when exposed to elevated levels of oxidative stress. Like Thr287 autophosphorylation, Met281/ Met282 oxidation prevents reassociation of the catalytic and regulatory domains even in the absence of $\mathrm{Ca} 2+/ \mathrm{CaM}$ binding either $[10,18]$. And also oxidation may increase the sensitivity of CaMKII to activation by $\mathrm{Ca} 2+/ \mathrm{CaM}$ and the abundance of Thr287-autophosphorylated CaMKII by inactivating phosphatases [12].

The underlying mechanisms for CaMKII activation during hyperglycemia and diabetes through the addition of an O-GlcNAC modification was found in recent study.

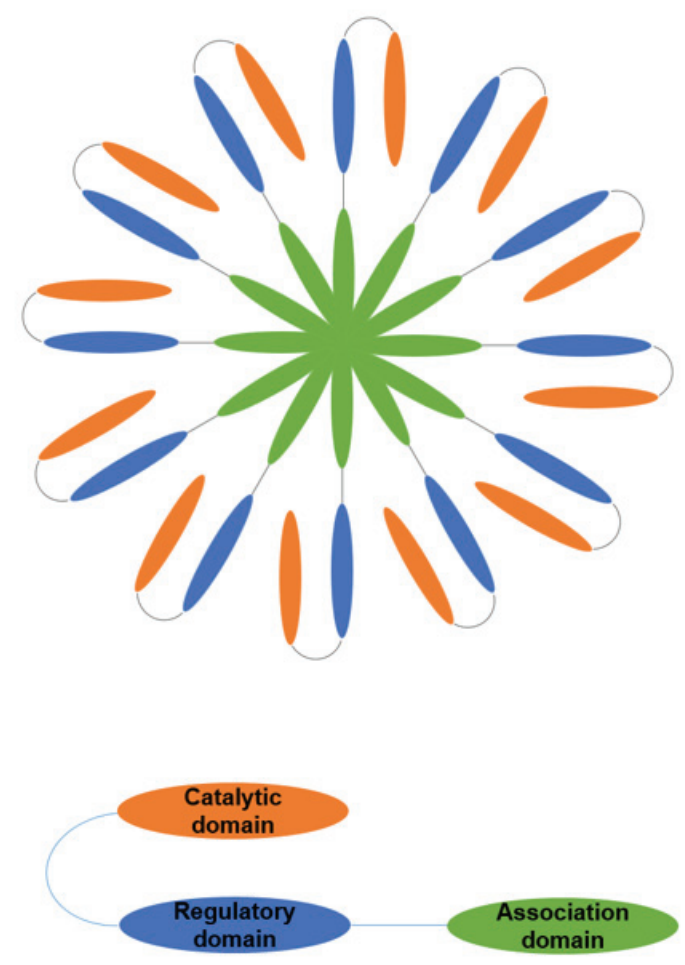

Figure 1: Schematic depiction of the $\mathrm{Ca} 2+/$ calmodulin dependent protein kinase II (CaMKII) structure. CaMKII holoenzyme is a dodecamer (top) and each monomer has the association domain, regulatory domain, and catalytic domain (bottom).
O-GlcNAc modification of CaMKII at Ser279 activated CaMKII autonomously, creating molecular memory even after $\mathrm{Ca} 2+$ concentration declines [19]. In addition, CaMKII can be activated via nitric oxide (NO)-dependent nitrosylation of Cys273 or Cys290, the exact mechanism is still unknown at present [20] (Figure 2).

\section{THE ROLE OF CAMKII IN CANCER PROGRESSION}

\section{Cell proliferation}

Some studies have implicated CaMKII as an important player in cancer cell proliferation. The pharmacologic inhibition of CaMKII in MG-63 and 143B human osteosarcoma cells by KN-93, a chemical inhibitor of CaMKII, resulted in an 80 and $70 \%$ decrease in proliferation, respectively. The in vivo administration of KN-93 to mice xenografted with human osteosarcoma cells significantly decreased intratibial and subcutaneous tumor growth. And the inhibitory effect of CaMKII was associated with increased $\mathrm{p} 21^{\mathrm{CIP} / \mathrm{KI}}$ gene expression, protein levels, and decreased the phosphorylation of retinoblastoma $(\mathrm{Rb})$ protein and E2F transactivation [21]. In normal and neoplastic B-lymphoid cells, suppression of CaMKII prevented the excessive B-cell activating factor (BAFF) -induced aggressive B-cell malignancies. It appeared that human soluble BAFF (hsBAFF)-mediated cell proliferation and survival was $\mathrm{Ca} 2+-\mathrm{CaMKII}-$ dependent [22]. In chronic myeloid leukemia (CML), cell proliferation specifically depends on activation of the CaMKII $\gamma$ isoforms. CML cells undergoing terminal differentiation or growth arrest display a marked reduction of CaMKII $\gamma$ autophosphorylation. Inhibition of CaMKII $\gamma$ resulted in the suppression of myeloid leukemia cell proliferation. The inhibitory effect of CaMKII $\gamma$ related to multiple signaling pathways, including mitogen-activated protein kinase (MAPK), signal transducer and activator of transcription 3(Stat3)/Stat5, and glycogen synthase kinase $3 \beta(\mathrm{GSK} 3 \beta) / \beta$-catenin pathways [23]. Recently, Monaco et al. [24] reported that inhibition of CaMKII activity resulted in an upregulation of CaMKIV mRNA and protein in myeloid leukemia cell lines. Conversely, expression of CaMKIV inhibited autophosphorylation and activation of CaMKII, and elicited $\mathrm{G}_{0} / \mathrm{G}_{1}$ cell cycle arrest, impairing cell proliferation. These data reveal a novel cross-talk between CaMKII and CaMKIV and suggest that CaMKII suppresses the expression of CaMKIV to promote leukemia cell proliferation. CaMKII $\gamma$ promoted the cell proliferation via direct activation of nuclear factor kappa-light-chain-enhancer of activated B cells $(\mathrm{NF}-\kappa \mathrm{B})$ and multiple oncogenic signaling pathways in non-small cell lung cancer (NSCLC) was found by Chai et al. CaMKII $\gamma$ could phosphorylate I $\kappa \mathrm{B} \alpha$ kinase 
$\beta$ (IKK $\beta$ ) at Ser177/181 and functioned as a mediator of IKK $\beta$ activation in NSCLC. In the meanwhile, CaMKII $\gamma$ could directly or indirectly upregulate multiple signaling pathways such as extracellular signal-regulated kinase $1 / 2$ (Erk1/2), protein kinase B (Akt1), Stat3, and $\beta$-catenin and involve in regulating the survival and proliferation of NSCLC cells [5]. In papillary thyroid carcinoma (PTC), CaMKII is activated by BRaf ${ }^{\mathrm{V} 600 \mathrm{E}}$, Ras, and by RET/ PTC. The activation of CaMKII subsequently leads to Erk activation and cell proliferation. Inhibition of CaMKII attenuates Erk activation and DNA synthesis in PTC cells [25]. Furthermore, the cell proliferation effects of CaMKII depend on the phosphorylated sites was found by Hoffman et al. [26]. They showed that the overexpression of a wildtype or Thr286 phosphomimic form of CaMKII increased proliferation rates of neuroblastoma and breast cancer cells, whereas overexpression of a Thr253 phosphomimic form significantly reduced proliferation rates in these cells.

\section{Cell cycle effects}

CaMKII involves in the cell cycle control with a complex manner and associates with multiple cell signaling pathways (Figure 3 ). In colon adenocarcinoma cells, CaMKII activates mitogen-activated/extracellular regulated kinase $(\mathrm{MEK}) / \mathrm{Erk}$, which is responsible for the phosphorylation and subsequent proteasomal degradation of cyclin-dependent kinase inhibitor $1 \mathrm{~B}$ (p27 $\left.7^{\mathrm{Kip} 1}\right)$, thus causing the promotion of the $\mathrm{S}-\mathrm{G}_{2} / \mathrm{M}$ transition of cell cycle progression [27]. In osteosarcoma cells, CaMKII $\alpha$ increases the phosphorylation of T-lymphoma and metastasis gene 1 (Tiam1) and its membrane localization, and then activates ras-related $\mathrm{C} 3$ botulinum toxin substrate 1(Rac1), inhibits the expression of $\mathrm{p} 21^{\mathrm{CIP} /}$ KIP and leads to a cell cycle progression [21]. In HeLa cells, CaMKII phosphorylates cell division cycle $25 \mathrm{c}$ $(\operatorname{cdc} 25 \mathrm{c})$ and enhances $\mathrm{G}_{2} / \mathrm{M}$ transition. Treatment of a synchronous population of HeLa cells with KN-93 or the microinjection of AC3-I (a specific peptide inhibitor of CaMKII) resulted in a cell cycle block in $\mathrm{G}_{2}$ phase [28]. In breast cancer cells, CaMKII triggers the export of breast cancer susceptibility gene 1 (BRCA1) from nucleus and decreases the BRCA1-dependent expression of $\mathrm{p} 21^{\mathrm{CIP} /}$ KIP [29]. Moreover, CaMKII also can stimulate Cyclin D1 expression via NF- $\mathrm{KB}$ in breast cancer cells, which results in promoting of $\mathrm{G}_{1} / \mathrm{S}$ transition [30]. In addition to the promotion of cell cycle progression, CaMKII also can block the cell cycle of different cancers. CaMKII may suppress cell cycle progression by stabilization of $\mathrm{p} 53$ via CaMKII-dependent phosphorylation of the RING-H2 type E3 ligase (Pirh2) in breast and lung cancer cell lines [31].

\section{Invasion and metastasis}

More and more evidences support the critical role of CaMKII in cancer invasion and metastasis. Daft et al. [32] demonstrated that the upregulation of CaMKII $\alpha$ was found in primary osteosarcoma tissues

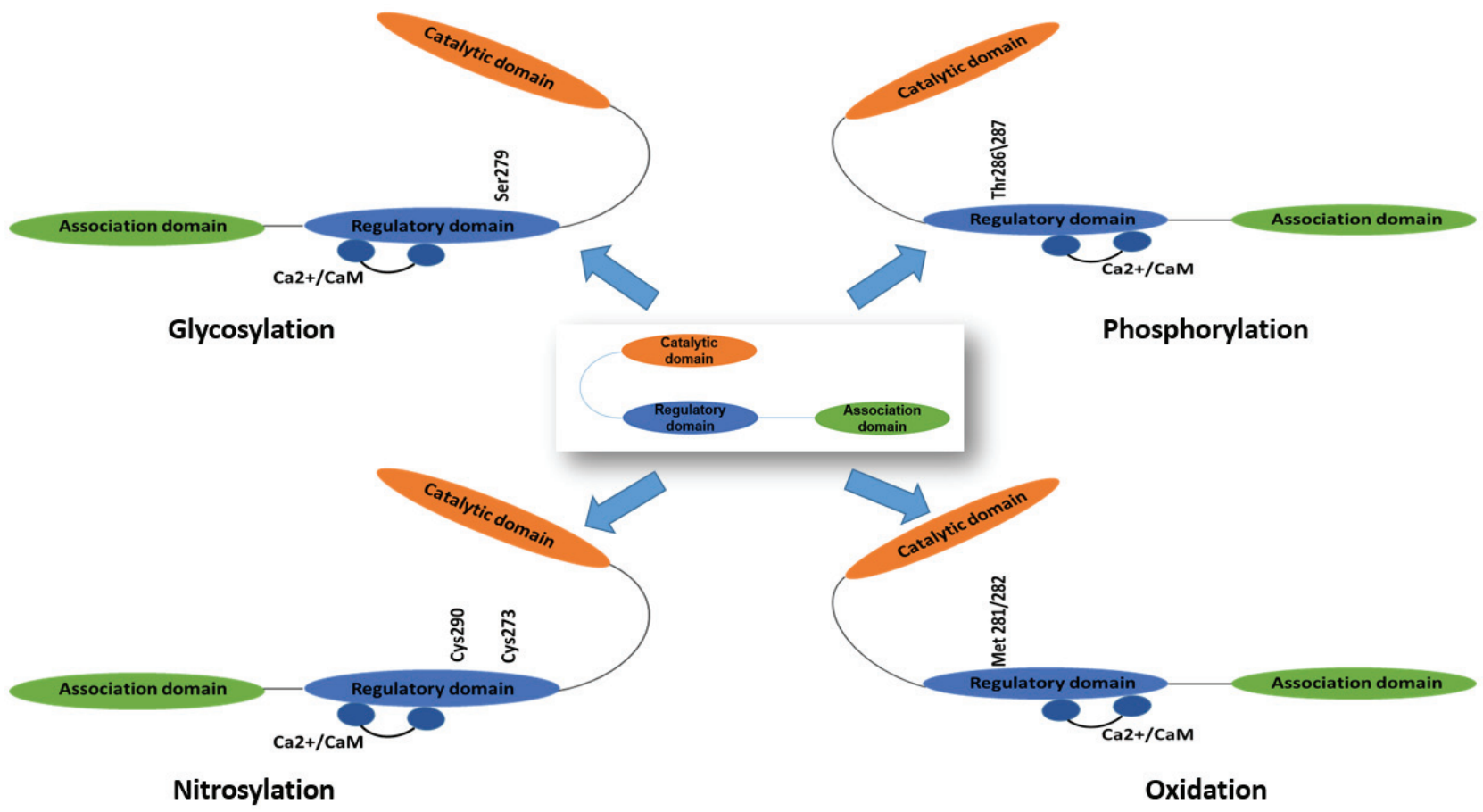

Figure 2: The activation mechanisms of Ca2+/calmodulin dependent protein kinase II (CaMKII). CaMKII could be activated by phosphorylation, oxidation, nitrosylation and glycosylation. 
from patients and in aggressive osteosarcoma cell lines. The knockdown of CaMKII $\alpha$ decreases motility and invasion, whereas $\mathrm{CaMKII} \alpha$ overexpression increases the tumorigenic properties of osteosarcoma cell lines in vitro. Wang et al. [33] found that the activation of CaMKII significantly increased cell motility and the capacity of wound healing in prostate cancer cell lines. The rate of wound closure was decreased by $80 \%$ after inhibition of CaMKII. Bourguignon et al. [34] showed that CaMKII involved in hyaluronan (HA)-CD44mediated signaling and modulated the adhesion and migration of head and neck squamous cell carcinoma (HNSCC) cells. HA-CD44 binding induces the leukemiaassociated Rho guanine nucleotide exchange factor (LARG)-specific RhoA signaling and phospholipase CE (PLCE) activity. The activation of RhoA- PLC $\varepsilon$ stimulates inositol 1,4,5-triphosphate production, intracellular $\mathrm{Ca} 2+$ mobilization, and subsequently activates CaMKII, leading to phosphorylation of the cytoskeletal protein, filamin. The phosphorylation of filamin reduces its interaction with filamentous actin, promoting HNSCC cell migration. Li et al. [35] reported that apoptosis regulatory protein Siva1 inhibited stathmin's activity through CaMKII dependent phosphorylation of stathmin at Ser16 in breast cancer cells. The formation of microtubules and impedes focal adhesion assembly, cell migration, and epithelial-mesenchymal transition (EMT) were enhanced by Sival via the inhibition of stathmin. Cuddapah et al. [36] indicated that the interaction of $\mathrm{ClC}-3$ and $\mathrm{CaMKII}$ played critical role in the invasion and metastasis properties of glioma cells. CaMKII phosphorylated $\mathrm{ClC}-3$ at Ser109 and led to an increase in ClC-3 current. ClC-3 enhances migration of glioma cells, and pharmacological inhibition with NPPB2 demonstrates a requirement for chloride channels to support the glioma invasion. In addition, recent evidence elucidates that bradykinin increases human glioma cell motility. Bradykinin activates the bradykinin receptor B2 (B2R), leading to increases in $\mathrm{Ca} 2+$ and enhanced the migration of glioma cells. The action of bradykinin in glioma is related to $\mathrm{Ca} 2+$-activated $\mathrm{Cl}$ currents, which is modulated by CaMKII [37]. Umemura et al.[38] found another mechanism of CaMKII involving cancer cell invasion. They showed that store-operated $\mathrm{Ca} 2+$ entry (SOCE) promoted melanoma progression by enhancing cell invasion and metastasis through activation of Erk signaling via the CaMKII/Raf-1/Erk pathway, irrespective of the status of Braf. Najdi et al. [39] proposed that CaMKII involved in the auto-activating loop of Wnt and CaMKII, and skew the balance of T-cell factors (TCFs). Inappropriate activation of this signal pathway would contribute to the cause and aggressive behavior of colon cancer cells.

\section{Apoptosis}

The anti-apoptotic activity of CaMKII was found in recent studies. One anti-apoptotic pathway utilized by CaMKII is inhibition of caspase expression at the procaspase level and inhibition of caspase activation. Overexpression of CaMKII resulted in inhibition of procaspase- 7 and procaspase- 8 expression. And the activation of caspase- $2,-7$, and -8 could be prevented or diminished by overexpression of CaMKII [40]. Cohen et al.[41] reported that downregulation of ErbB could suppress the CaMKII signaling, which is coincident with the induction of apoptosis in breast and prostate cancer cells.

\section{THE ROLE OF CAMKII AS A BIOMARKER IN CANCER DIAGNOSIS}

The role of CaMKII as a biomarker in cancer diagnosis was evaluated in some studies. Epigenetic regulation of gene expression through changes in $\mathrm{CpG}$ methylation in the promoter plays pivotal roles during cancioigenesis. Kim et al. [42] found that normal breast cells and breast cancer cells had different CaMKII $\beta$ promoter methylation status. Based on this result, they suggested the promoter methylations of CaMKII $\beta$ can be used as a biomarker for the diagnosis of breast cancer. Mamaeva et al. [43] showed that the expression profile of CaMKII isoforms was tissue-specific and could be used as a biomarker to distinguish the origination of cancer cells. They examined the gene expression of the four isoforms of CaMKII: $\alpha, \beta, \gamma$, and $\delta$ in prostate cancer cell line C4-2B, PC3, LNCaP, and DU145. Only C4-2B and PC-3 cells, which are both derived from bone metastases, express all four isoforms of CaMKII. In another study, expression profiling of primary tumor tissues from 12 colon and 12 rectal cancers was performed using oligonucleotide microarray analysis. Of the genes differentially expressed between colon and rectal cancer, CaMKII $\gamma$ was one of the most significantly altered. CaMKII $\gamma$ provides potential candidate for distinguishing between colon and rectal cancer [44]. In a recent study, Chai et al. [5] demonstrated that CaMKII $\gamma$ was aberrantly expressed in human NSCLC tissues and correlated well with the degree of malignancy, and CaMKII $\gamma$ could be used as a potential biomarker of malignancy for NSCLC. Cancer cachexia is a syndrome associated with malignant tumor disease defined by weight loss, asthenia and anorexia. Stephens et al. [45] indicated that CaMKII $\beta$ directly involved in human cancer cachexia. The activation of CaMKII $\beta$ appears to be a general marker of muscle wasting in human cancer cachexia. 


\section{THE ROLE OF CAMKII IN CANCER THERAPY}

\section{Therapy resistance}

Cellular Fas-associating protein with a novel death domain (FADD)-like interleukin-1 $\beta$-converting enzyme inhibitory protein (c-FLIP), contributes to cancer therapy resistance has been demonstrated in some studies [46-48]. Yang et al. reported that the expression and phosphorylation of $\mathrm{c}-\mathrm{FLIP}_{\mathrm{L}}$ proteins was regulated by CaMKII [49]. When CaMKII activity was inhibited, c-FLIP expression reduced and the resistance glioma cells became sensitive to Fas-mediated apoptosis [50]. The similar results was also found in melanoma cells. KN-93 could sensitize resistant melanoma cells to TNFrelated apoptosis-inducing ligand (TRAIL)-induced apoptosis via downregulated of c-FLIP proteins [51]. In addition, Rodriguez-Mora et al. [52] indicated that CaMK inhibitor could increase the treatment efficacy of doxorubicin, ionizing radiation, or photodynamic therapy in breast cancer cells. CaMKII participated in hydrogen peroxide-induced Erk phosphorylation was considered to be the underlying mechanism. Riganti et al. [53] showed that the transient increase of $\mathrm{Ca} 2+$ may activate CaMKII, which in turn phosphorylated and activated the transcription factor hypoxia-inducible factors $1 \alpha$ (HIF$1 \alpha$ ) in colon cancer cells. As a consequence of HIF-1 $\alpha$ nuclear translocation, P-glycoprotein 1 is overexpressed, intracellular accumulation of doxorubicin is reduced and cytotoxic effects of doxorubicin are prevented. These studies propose the critical role of CaMKII in cancer therapy resistance and targeting these pathways may provide novel therapeutic strategies in treatment of cancer.

\section{Modulation of therapy efficiency}

For patients with inoperable or disseminated neuroblastoma, one of the most actively employed treatment approaches is targeted radiotherapy using ${ }^{131}$ I-labeled metaiodobenzylguanidine (MIBG) [54]. The efficacy of ${ }^{131} \mathrm{I}-\mathrm{MIBG}$ therapy is related to norepinephrine transporter (NET), which activity is largely modulated through specific intracellular signaling cascades, and candidate pathways for its regulation including protein

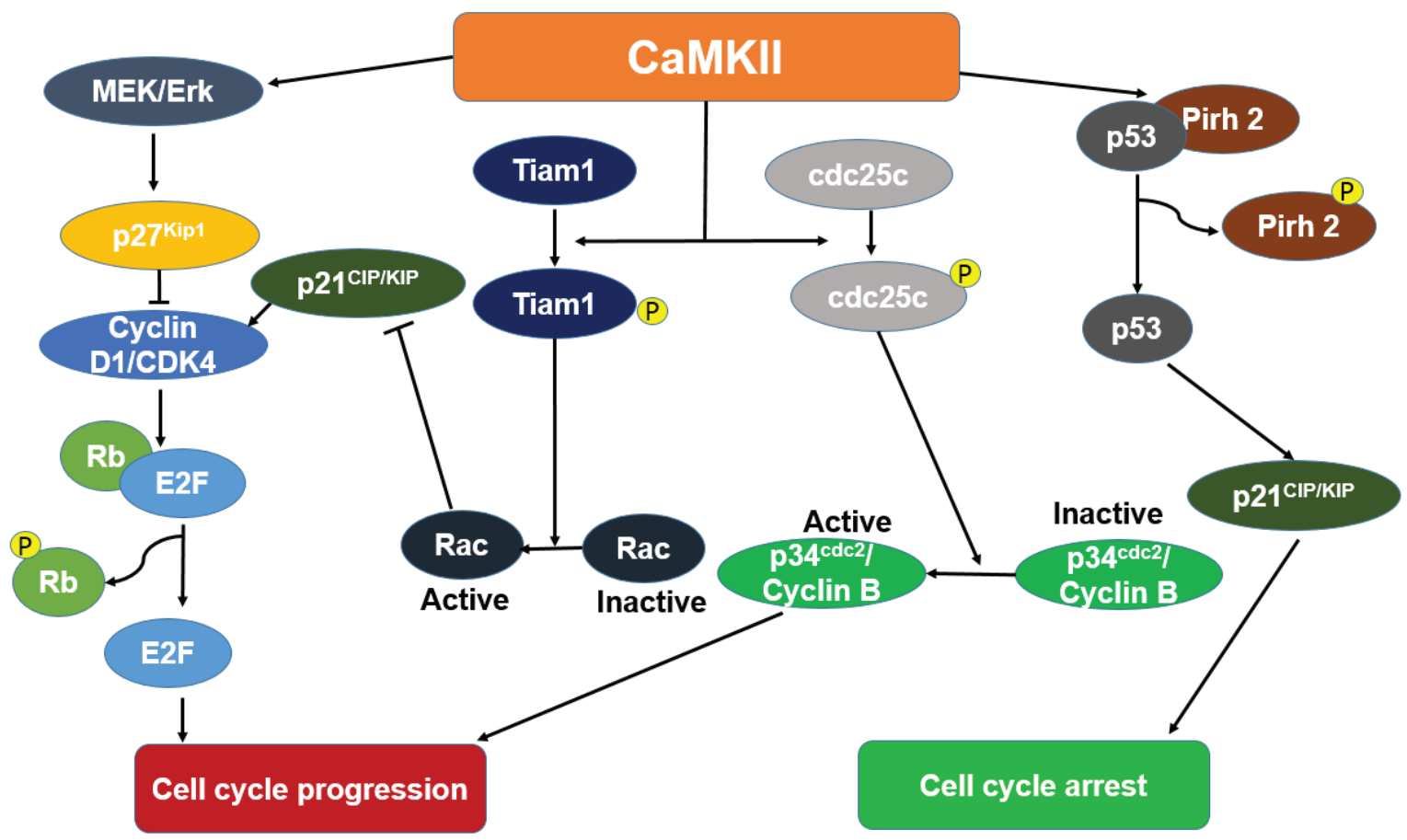

Figure 3: The proposed mechanisms depicting the cell cycle effect of $\mathrm{Ca}+$ /calmodulin dependent protein kinase II (CaMKII) in cancer. CaMKII activates cyclin-dependent kinase inhibitor 1B (p27 ${ }^{\text {Kipl} 1) ~ v i a ~ t h e ~ m i t o g e n-a c t i v a t e d / e x t r a c e l l u l a r ~}$ regulated kinase (MEK)/extracellular signal-regulated kinase (Erk) pathway. Activated p27 ${ }^{\mathrm{kip} 1}$ will then inhibit cyclin-dependent kinase $4(\mathrm{Cdk} 4) /$ CyclinD1 complexes, and therefore retinoblastoma $(\mathrm{Rb})$ phosphorylation and E2F activation, induce cell cycle progression. CaMKII phosphorylates T-lymphoma and metastasis gene 1 (Tiam1) and then increases the activation of ras-related C3 botulinum toxin substrate 1(Rac1). The activation of Rac1 inhibits the expression of $\mathrm{p} 21^{\mathrm{CIP} / \mathrm{KIP}}$. This leads to a cell cycle progression. CaMKII increases the phosphorylation of cell division cycle $25 \mathrm{c}(\mathrm{cdc} 25 \mathrm{c})$ and actives $\mathrm{p} 34^{\mathrm{cdc} 2} / \mathrm{Cyclin} \mathrm{B}$, causes the cell cycle progression. CaMKII suppresses cell cycle progression by stabilization of p53 via CaMKII-dependent phosphorylation of RING-H2 type E3 ligase (Pirh2). 
kinase $\mathrm{C}$ (PKC), mitogen activated protein kinase (MAPK), phosphatidyl inositol-3 kinase (PI3K), and CaMKII [55]. Melittin, a water-soluble 26-amino acid peptide derived from bee venom of Apis mellifera, can exert toxic or inhibitory effects on many types of cancer cells [56-58]. Wang et al. [59] demonstrated that melittin potentiated the TRAIL induced apoptotic effects in human hepatocellular carcinoma cells by activating the CaMKII- transforming growth factor- $\beta$-activated kinase 1 (TAK1)- c-Jun N-terminal kinase (JNK)/p38 pathway but inhibiting the IKK-NFкB pathway. Fucoidan, a fucoserich polysaccharide, is isolated from brown seaweed such as Cladosiphon okamuranus and Fucus evanescens. Recent studies have reported its various biological activities including anti-inflammatory, anti-coagulant, and anti-cancer $[60,61]$. Chen et al. [62] indicated that fucoidan treatment inhibited cell growth and induced apoptosis in breast and colon cancer though the promotion of endoplasmic reticulum (ER) $\mathrm{Ca} 2+$-dependent CaMKII phosphorylation. Additionally, fucoidan has been linked to the increase of ER-stress and release of $\mathrm{Ca} 2+$ intracellularly. Cytosolic $\mathrm{Ca} 2+$ binds to calmodulin to activate CaMKII signalling, leading to ER stress-induced cell apoptosis through activating the mitochondrial apoptosis pathway[63].

\section{CAMKII INHIBITORS}

During last two decades, a number of CaMKII inhibitors have been synthesized or found $[14,64]$. Current knowledge about CaMKII control on physiological or pathological functions is largely based on the researches on these inhibitors. The most widely used inhibitor for study of cellular and in vivo functions of CaMKII has been KN-93 and KN-62. KN-93 and KN-62 share the same structural elements and mechanism of action. Inhibition by both is competitive with $\mathrm{Ca} 2+/ \mathrm{CaM}$ and not competitive with ATP [14]. KN-93 and KN-62 have been found to induce cell cycle arrest in a variety of cancer cells. The $\mathrm{G}_{1}$ and/or $\mathrm{S}$ phase arrest effect of KN-93 and KN-62 on K562 and HeLa cells has been reported [65, 66]. KN-93 decreased cyclin-dependent kinase (cdk) 4 activity by reducing Cyclin D1 levels and cdk2 activity by enhancing p2 $7^{\mathrm{Kip} 1}$ expression, causing cell cycle blocked at the $\mathrm{G}_{1}$ phase [67]. However, one of the limitations of KN-93 and $\mathrm{KN}-62$ is low potency and absence of highly specific inhibition. KN-93 and KN-62 cannot discriminate between CaMKII and CaMKIV and also inhibit voltage-gated $\mathrm{K}+$ and $\mathrm{Ca} 2+$ channels $[68,69]$. Another limitation of $\mathrm{KN}$ 93 and KN-62 is that these compounds inhibit CaMKII activity by interfering with their binding to the $\mathrm{Ca} 2+/ \mathrm{CaM}$ complex. However, once CaMKII has become activated (autophosphorylated), its dependence on further $\mathrm{Ca} 2+$ / CaM binding is markedly diminished [17]. Thus, these compounds exert considerably less inhibition on CaMKII once it has become activated (autophosphorylated) [23].
CaMKII inhibitor 1 (CaMKIIN1), a peptide composed of 78-amino acids, functions as a potent and specific inhibitor of CaMKII was investigated recently. Wang et al. [70] found that CaMKIIN1 could inhibit prostate cancer growth in vivo. The inhibition effect was attributed to the down-regulation of insulin-like growth factor 1 (IGF-1), ErbB2, and vascular endothelial growth factor (VEGF) downstream kinases PI3K/Akt, as well as the MEK/Erk-mediated signaling pathways. Cao et al. [8, 71] identified human CaMKII inhibitory proteins, hCaMKIIN $\alpha$ and hCaMKIIN $\beta$, which directly interacted with activated CaMKII and effectively inhibits CaMKII activity. hCaMKIIN $\alpha$ could inhibit human colon adenocarcinoma cell growth both in vitro and in vivo by arresting cell cycle at the $\mathrm{S}$ phase. The effect of hCaMKIIN $\alpha$ on cell cycle is correlated with upregulation of $\mathrm{p} 27^{\mathrm{Kip} 1}$ expression, which may be due to the inhibition of proteasome degradation of $\mathrm{p} 27^{\mathrm{Kip} 1}$. Moreover, hCaMKIIN $\alpha$ may suppress the activity of MEK/ Erk, which is prerequisite to the inhibition of Thr187 phosphorylation and subsequent proteasomal degradation of $\mathrm{p} 27^{\mathrm{Kip} 1}$, causing the inhibition of $\mathrm{S}$ phase progression of cell cycle. For hCaMKIIN $\beta$, the cell cycle arrest effect was depended on the upregulation of $\mathrm{p} 21^{\mathrm{CIP} / \mathrm{KIP}}, \mathrm{p} 53$, and B-cell lymphoma 2 (Bcl-2)-associated X protein (Bax) and downregulation of Cyclin A, Cyclin D1, Cyclin E, Cyclin-dependent kinase 2 (CDK2), phosphorylated Rb, and Bcl-2 [72].

Other CaMKII inhibitors include some small molecules such as bosutinib, berberine, and berbamine. In contrast to other CaMKII inhibitors, which interfere with $\mathrm{Ca} 2+/ \mathrm{CaM}$ complex formation, bosutinib directly targets the adenosine triphosphate binding site of CaMKII $\gamma$ and exerts the CaMKII inhibition effect [73]. Berberine, which is an isoquinoline alkaloid, decreases phosphorylation of CaMKII and blocks subsequent MEK1 activation as well as $\mathrm{p} 27^{\mathrm{Kip} 1}$ protein degradation in human hepatoma cells [74]. Berbamine is a structurally unique bisbenzylisoquinoline isolated from Berberis amurensis. It can specifically bind to the ATP binding pocket of CaMKII, inhibits its phosphorylation and triggers apoptosis of leukemia cells [75]. In addition, Berbamine could suppress the growth of liver cancer cells in vitro and in vivo through inhibited CAMKII phosphorylation and directly down-regulated CAMKII [76].

\section{CONCLUSIONS}

Strong evidences now show that CaMKII has emerged as a key nodal protein in the modulation of cell proliferation, cell cycle, invasion and metastasis, and therapy efficacy in variety of malignant diseases. These data establish CaMKII as a novel therapeutic target whose modulation presents new opportunities for cancer treatment. In this review, we also describe the role of CaMKII in the diagnosis of different kinds of cancer and 
recent progress in the development of CaMKII inhibitors. Although our knowledge about CaMKII is advancing, major questions still remain. Due to the particularly elegant relationship between the structure and function of the kinase, CaMKII is able to translate a diverse set of signaling events into downstream physiological effects. If we hope to use this kinase deeply in cancer diagnosis and therapy, we also need improve the understanding of CaMKII activation mechanisms. Additionally, the development of clinically applicable CaMKII inhibitory drugs to test the clinical benefit of CaMKII inhibition is also very important in the future researches.

\section{CONFLICTS OF INTEREST}

None

\section{REFERRENCES}

1. Orrenius, S., B. Zhivotovsky, and P. Nicotera. Regulation of cell death: the calcium-apoptosis link. Nat Rev Mol Cell Biol. 2003; 4: 552-65.

2. Nowycky, M.C. and A.P. Thomas. Intracellular calcium signaling. J Cell Sci. 2002; 115: 3715-6.

3. Griffith, W.H., M.C. Jasek, S.H. Bain, and D. Murchison. Modification of ion channels and calcium homeostasis of basal forebrain neurons during aging. Behav Brain Res. 2000; 115: 219-33.

4. Hook, S.S. and A.R. Means. $\mathrm{Ca}(2+) / \mathrm{CaM}-$ dependent kinases: from activation to function. Annu Rev Pharmacol Toxicol. 2001; 41: 471-505.

5. Chai, S., Y. Qian, J. Tang, Z. Liang, M. Zhang, J. Si, X. Li, W. Huang, R. Xu, and K. Wang. Ca(2+)/calmodulindependent protein kinase IIgamma, a critical mediator of the NF-kappaB network, is a novel therapeutic target in nonsmall cell lung cancer. Cancer Lett. 2014; 344: 119-28.

6. Britschgi, A., A. Bill, H. Brinkhaus, C. Rothwell, I. Clay, S. Duss, M. Rebhan, P. Raman, C.T. Guy, K. Wetzel, E. George, M.O. Popa, S. Lilley, et al. Calcium-activated chloride channel ANO1 promotes breast cancer progression by activating EGFR and CAMK signaling. Proc Natl Acad Sci U S A. 2013; 110: E1026-34

7. Wang, T., S. Guo, Z. Liu, L. Wu, M. Li, J. Yang, R. Chen, X. Liu, H. Xu, S. Cai, H. Chen, W. Li, S. Xu, et al. CAMK2N1 inhibits prostate cancer progression through androgen receptor-dependent signaling. Oncotarget. 2014; 5: 10293-306.

8. Wang, C., N. Li, X. Liu, Y. Zheng, and X. Cao. A novel endogenous human CaMKII inhibitory protein suppresses tumor growth by inducing cell cycle arrest via p27 stabilization. J Biol Chem. 2008; 283: 11565-74.

9. Lisman, J., R. Yasuda, and S. Raghavachari. Mechanisms of CaMKII action in long-term potentiation. Nat Rev Neurosci. 2012; 13: 169-82.
10. Erickson, J.R. Mechanisms of CaMKII Activation in the Heart. Front Pharmacol. 2014; 5: 59.

11. Hoelz, A., A.C. Nairn, and J. Kuriyan. Crystal structure of a tetradecameric assembly of the association domain of $\mathrm{Ca} 2+1$ calmodulin-dependent kinase II. Mol Cell. 2003; 11: 124151.

12. Rokita, A.G. and M.E. Anderson. New therapeutic targets in cardiology: arrhythmias and $\mathrm{Ca} 2+$ /calmodulin-dependent kinase II (CaMKII). Circulation. 2012; 126: 2125-39.

13. Srinivasan, M., C.F. Edman, and H. Schulman. Alternative splicing introduces a nuclear localization signal that targets multifunctional CaM kinase to the nucleus. J Cell Biol. 1994; 126: 839-52.

14. Pellicena, P. and H. Schulman. CaMKII inhibitors: from research tools to therapeutic agents. Front Pharmacol. 2014; 5: 21 .

15. Gaertner, T.R., S.J. Kolodziej, D. Wang, R. Kobayashi, J.M. Koomen, J.K. Stoops, and M.N. Waxham. Comparative analyses of the three-dimensional structures and enzymatic properties of alpha, beta, gamma and delta isoforms of Ca2+-calmodulin-dependent protein kinase II. J Biol Chem. 2004; 279: 12484-94.

16. Fong, Y.L., W.L. Taylor, A.R. Means, and T.R. Soderling. Studies of the regulatory mechanism of $\mathrm{Ca} 2+/$ calmodulindependent protein kinase II. Mutation of threonine 286 to alanine and aspartate. J Biol Chem. 1989; 264: 16759-63.

17. Meyer, T., P.I. Hanson, L. Stryer, and H. Schulman. Calmodulin trapping by calcium-calmodulin-dependent protein kinase. Science. 1992; 256: 1199-202.

18. Erickson, J.R., M.L. Joiner, X. Guan, W. Kutschke, J. Yang, C.V. Oddis, R.K. Bartlett, J.S. Lowe, S.E. O’Donnell, N. Aykin-Burns, M.C. Zimmerman, K. Zimmerman, A.J. Ham, et al. A dynamic pathway for calcium-independent activation of CaMKII by methionine oxidation. Cell. 2008; 133: 462-74.

19. Erickson, J.R., L. Pereira, L. Wang, G. Han, A. Ferguson, K. Dao, R.J. Copeland, F. Despa, G.W. Hart, C.M. Ripplinger, and D.M. Bers. Diabetic hyperglycaemia activates CaMKII and arrhythmias by O-linked glycosylation. Nature. 2013; 502: 372-6.

20. Gutierrez, D.A., M. Fernandez-Tenorio, J. Ogrodnik, and E. Niggli. NO-dependent CaMKII activation during betaadrenergic stimulation of cardiac muscle. Cardiovasc Res. 2013; 100: 392-401.

21. Yuan, K., L.W. Chung, G.P. Siegal, and M. Zayzafoon. alpha-CaMKII controls the growth of human osteosarcoma by regulating cell cycle progression. Lab Invest. 2007; 87: 938-50.

22. Liang, D., Q. Zeng, Z. Xu, H. Zhang, L. Gui, C. Xu, S. Chen, S. Zhang, S. Huang, and L. Chen. BAFF activates Erk1/2 promoting cell proliferation and survival by $\mathrm{Ca} 2+-$ CaMKII-dependent inhibition of PP2A in normal and neoplastic B-lymphoid cells. Biochem Pharmacol. 2014; 87: 332-43. 
23. $\mathrm{Si}, \mathrm{J}$. and S.J. Collins. Activated $\mathrm{Ca} 2+/$ calmodulindependent protein kinase IIgamma is a critical regulator of myeloid leukemia cell proliferation. Cancer Res. 2008; 68: 3733-42.

24. Monaco, S., M.R. Rusciano, A.S. Maione, M. Soprano, R. Gomathinayagam, L.R. Todd, P. Campiglia, S. Salzano, L. Pastore, E. Leggiero, D.C. Wilkerson, M. Rocco, C. Selleri, et al. A novel crosstalk between calcium/calmodulin kinases II and IV regulates cell proliferation in myeloid leukemia cells. Cell Signal. 2015; 27: 204-14.

25. Rusciano, M.R., M. Salzano, S. Monaco, M.R. Sapio, M. Illario, V. De Falco, M. Santoro, P. Campiglia, L. Pastore, G. Fenzi, G. Rossi, and M. Vitale. The Ca2+-calmodulindependent kinase II is activated in papillary thyroid carcinoma (PTC) and mediates cell proliferation stimulated by RET/PTC. Endocr Relat Cancer. 2010; 17: 113-23.

26. Hoffman, A., H. Carpenter, R. Kahl, L.F. Watt, P.W. Dickson, J.A. Rostas, N.M. Verrills, and K.A. Skelding. Dephosphorylation of CaMKII at T253 controls the metaphase-anaphase transition. Cell Signal. 2014; 26: 74856.

27. Li, N., C. Wang, Y. Wu, X. Liu, and X. Cao. Ca(2+)/ calmodulin-dependent protein kinase II promotes cell cycle progression by directly activating MEK1 and subsequently modulating p27 phosphorylation. J Biol Chem. 2009; 284: 3021-7.

28. Patel, R., M. Holt, R. Philipova, S. Moss, H. Schulman, H. Hidaka, and M. Whitaker. Calcium/calmodulin-dependent phosphorylation and activation of human $\mathrm{Cdc} 25-\mathrm{C}$ at the G2/M phase transition in HeLa cells. J Biol Chem. 1999; 274: 7958-68.

29. Glover-Collins, K. and M.E. Thompson. Nuclear export of BRCA1 occurs during early $\mathrm{S}$ phase and is calciumdependent. Cell Signal. 2008; 20: 958-68.

30. Torricelli, C., V. Fortino, E. Capurro, G. Valacchi, A. Pacini, M. Muscettola, K. Soucek, and E. Maioli. Rottlerin inhibits the nuclear factor kappaB/cyclin-D1 cascade in MCF-7 breast cancer cells. Life Sci. 2008; 82: 638-43.

31. Duan, S., Z. Yao, D. Hou, Z. Wu, W.G. Zhu, and M. Wu. Phosphorylation of Pirh2 by calmodulin-dependent kinase II impairs its ability to ubiquitinate p53. EMBO J. 2007; 26: 3062-74.

32. Daft, P.G., K. Yuan, J.M. Warram, M.J. Klein, G.P. Siegal, and M. Zayzafoon. Alpha-CaMKII plays a critical role in determining the aggressive behavior of human osteosarcoma. Mol Cancer Res. 2013; 11: 349-59.

33. Wang, Q., A.J. Symes, C.A. Kane, A. Freeman, J. Nariculam, P. Munson, C. Thrasivoulou, J.R. Masters, and A. Ahmed. A novel role for $\mathrm{Wnt} / \mathrm{Ca} 2+$ signaling in actin cytoskeleton remodeling and cell motility in prostate cancer. PLoS One. 2010; 5: e10456.

34. Bourguignon, L.Y., E. Gilad, A. Brightman, F. Diedrich, and P. Singleton. Hyaluronan-CD44 interaction with leukemia-associated RhoGEF and epidermal growth factor receptor promotes $\mathrm{Rho} / \mathrm{Ras}$ co-activation, phospholipase $\mathrm{C}$ epsilon-Ca2+ signaling, and cytoskeleton modification in head and neck squamous cell carcinoma cells. J Biol Chem. 2006; 281: 14026-40.

35. Li, N., P. Jiang, W. Du, Z. Wu, C. Li, M. Qiao, X. Yang, and $\mathrm{M}$. Wu. Siva1 suppresses epithelial-mesenchymal transition and metastasis of tumor cells by inhibiting stathmin and stabilizing microtubules. Proc Natl Acad Sci U S A. 2011; 108: 12851-6.

36. Cuddapah, V.A. and H. Sontheimer. Molecular interaction and functional regulation of $\mathrm{ClC}-3$ by $\mathrm{Ca} 2+/$ calmodulindependent protein kinase II (CaMKII) in human malignant glioma. J Biol Chem. 2010; 285: 11188-96.

37. Cuddapah, V.A., K.L. Turner, S. Seifert, and H. Sontheimer. Bradykinin-induced chemotaxis of human gliomas requires the activation of KCa3.1 and ClC-3. J Neurosci. 2013; 33: 1427-40.

38. Umemura, M., E. Baljinnyam, S. Feske, M.S. De Lorenzo, L.H. Xie, X. Feng, K. Oda, A. Makino, T. Fujita, U. Yokoyama, M. Iwatsubo, S. Chen, J.S. Goydos, et al. Store-operated $\mathrm{Ca} 2+$ entry (SOCE) regulates melanoma proliferation and cell migration. PLoS One. 2014; 9: e89292.

39. Najdi, R., A. Syed, L. Arce, H. Theisen, J.H. Ting, F. Atcha, A.V. Nguyen, M. Martinez, R.F. Holcombe, R.A. Edwards, J.L. Marsh, and M.L. Waterman. A Wnt kinase network alters nuclear localization of TCF-1 in colon cancer. Oncogene. 2009; 28: 4133-46.

40. Hart, M.R., H.Y. Su, D. Broka, A. Goverdhan, and J.A. Schroeder. Inactive ERBB receptors cooperate with reactive oxygen species to suppress cancer progression. Mol Ther. 2013; 21: 1996-2007.

41. Cohen, M.B. and O.W. Rokhlin. Mechanisms of prostate cancer cell survival after inhibition of AR expression. J Cell Biochem. 2009; 106: 363-71.

42. Kim, J.H., T.W. Kim, and S.J. Kim. Downregulation of ARFGEF1 and CAMK2B by promoter hypermethylation in breast cancer cells. BMB Rep. 2011; 44: 523-8.

43. Mamaeva, O.A., J. Kim, G. Feng, and J.M. McDonald. Calcium/calmodulin-dependent kinase II regulates notch-1 signaling in prostate cancer cells. J Cell Biochem. 2009; 106: $25-32$.

44. Li, J.N., L. Zhao, J. Wu, B. Wu, H. Yang, H.H. Zhang, and J.M. Qian. Differences in gene expression profiles and carcinogenesis pathways between colon and rectal cancer. J Dig Dis. 2012; 13: 24-32.

45. Stephens, N.A., I.J. Gallagher, O. Rooyackers, R.J. Skipworth, B.H. Tan, T. Marstrand, J.A. Ross, D.C. Guttridge, L. Lundell, K.C. Fearon, and J.A. Timmons. Using transcriptomics to identify and validate novel biomarkers of human skeletal muscle cancer cachexia. Genome Med. 2010; 2: 1.

46. Irmler, M., M. Thome, M. Hahne, P. Schneider, K. Hofmann, V. Steiner, J.L. Bodmer, M. Schroter, K. Burns, 
C. Mattmann, D. Rimoldi, L.E. French, and J. Tschopp. Inhibition of death receptor signals by cellular FLIP. Nature. 1997; 388: 190-5.

47. Scaffidi, C., I. Schmitz, P.H. Krammer, and M.E. Peter. The role of c-FLIP in modulation of CD95-induced apoptosis. J Biol Chem. 1999; 274: 1541-8.

48. Siegmund, D., D. Mauri, N. Peters, P. Juo, M. Thome, M. Reichwein, J. Blenis, P. Scheurich, J. Tschopp, and H. Wajant. Fas-associated death domain protein (FADD) and caspase- 8 mediate up-regulation of c-Fos by Fas ligand and tumor necrosis factor-related apoptosis-inducing ligand (TRAIL) via a FLICE inhibitory protein (FLIP)-regulated pathway. J Biol Chem. 2001; 276: 32585-90.

49. Yang, B.F., C. Xiao, W.H. Roa, P.H. Krammer, and C. Hao. Calcium/calmodulin-dependent protein kinase II regulation of c-FLIP expression and phosphorylation in modulation of Fas-mediated signaling in malignant glioma cells. J Biol Chem. 2003; 278: 7043-50.

50. Yang, B.F., C. Xiao, H. Li, and S.J. Yang. Resistance to Fas-mediated apoptosis in malignant tumours is rescued by KN-93 and cisplatin via downregulation of c-FLIP expression and phosphorylation. Clin Exp Pharmacol Physiol. 2007; 34: 1245-51.

51. Xiao, C., B.F. Yang, J.H. Song, H. Schulman, L. Li, and C. Hao. Inhibition of CaMKII-mediated c-FLIP expression sensitizes malignant melanoma cells to TRAIL-induced apoptosis. Exp Cell Res. 2005; 304: 244-55.

52. Rodriguez-Mora, O.G., M.M. Lahair, M.J. Evans, C.J. Kovacs, R.R. Allison, C.H. Sibata, K.S. White, J.A. McCubrey, and R.A. Franklin. Inhibition of the CaMkinases augments cell death in response to oxygen radicals and oxygen radical inducing cancer therapies in MCF-7 human breast cancer cells. Cancer Biol Ther. 2006; 5: 102230 .

53. Riganti, C., S. Doublier, D. Viarisio, E. Miraglia, G. Pescarmona, D. Ghigo, and A. Bosia. Artemisinin induces doxorubicin resistance in human colon cancer cells via calcium-dependent activation of HIF-1alpha and P-glycoprotein overexpression. Br J Pharmacol. 2009; 156: 1054-66.

54. Matthay, K.K., R.E. George, and A.L. Yu. Promising therapeutic targets in neuroblastoma. Clin Cancer Res. 2012; 18: 2740-53.

55. Chung, H.W., J.W. Park, E.J. Lee, K.H. Jung, J.Y. Paik, and K.H. Lee. 131I-MIBG targeting of neuroblastoma cells is acutely enhanced by $\mathrm{KCl}$ stimulation through the calcium/ calmodulin-dependent kinase pathway. Cancer Biother Radiopharm. 2013; 28: 488-93.

56. Chu, S.T., H.H. Cheng, C.J. Huang, H.C. Chang, C.C. Chi, H.H. Su, S.S. Hsu, J.L. Wang, I.S. Chen, S.I. Liu, Y.C. Lu, J.K. Huang, C.M. Ho, et al. Phospholipase A2-independent $\mathrm{Ca} 2+$ entry and subsequent apoptosis induced by melittin in human MG63 osteosarcoma cells. Life Sci. 2007; 80: 364-9.

57. Li, B., W. Gu, C. Zhang, X.Q. Huang, K.Q. Han, and
C.Q. Ling. Growth arrest and apoptosis of the human hepatocellular carcinoma cell line BEL-7402 induced by melittin. Onkologie. 2006; 29: 367-71.

58. Liu, S., M. Yu, Y. He, L. Xiao, F. Wang, C. Song, S. Sun, C. Ling, and Z. Xu. Melittin prevents liver cancer cell metastasis through inhibition of the Rac1-dependent pathway. Hepatology. 2008; 47: 1964-73.

59. Wang, C., T. Chen, N. Zhang, M. Yang, B. Li, X. Lu, X. Cao, and C. Ling. Melittin, a major component of bee venom, sensitizes human hepatocellular carcinoma cells to tumor necrosis factor-related apoptosis-inducing ligand (TRAIL)-induced apoptosis by activating CaMKII-TAK1$\mathrm{JNK} / \mathrm{p} 38$ and inhibiting IkappaBalpha kinase-NFkappaB. J Biol Chem. 2009; 284: 3804-13.

60. Ale, M.T., J.D. Mikkelsen, and A.S. Meyer. Important determinants for fucoidan bioactivity: a critical review of structure-function relations and extraction methods for fucose-containing sulfated polysaccharides from brown seaweeds. Mar Drugs. 2011; 9: 2106-30.

61. Li, B., F. Lu, X. Wei, and R. Zhao. Fucoidan: structure and bioactivity. Molecules. 2008; 13: 1671-95.

62. Chen, S., Y. Zhao, Y. Zhang, and D. Zhang. Fucoidan induces cancer cell apoptosis by modulating the endoplasmic reticulum stress cascades. PLoS One. 2014; 9: e108157.

63. Timmins, J.M., L. Ozcan, T.A. Seimon, G. Li, C. Malagelada, J. Backs, T. Backs, R. Bassel-Duby, E.N. Olson, M.E. Anderson, and I. Tabas. Calcium/calmodulindependent protein kinase II links ER stress with Fas and mitochondrial apoptosis pathways. J Clin Invest. 2009; 119: 2925-41.

64. Gomez-Monterrey, I., M. Sala, M.R. Rusciano, S. Monaco, A.S. Maione, G. Iaccarino, P. Tortorella, A.M. D’Ursi, M. Scrima, A. Carotenuto, G. De Rosa, A. Bertamino, E. Vernieri, et al. Characterization of a selective CaMKII peptide inhibitor. Eur J Med Chem. 2013; 62: 425-34.

65. Minami, H., S. Inoue, and H. Hidaka. The effect of KN-62, $\mathrm{Ca} 2+/$ calmodulin dependent protein kinase II inhibitor on cell cycle. Biochem Biophys Res Commun. 1994; 199: 2418.

66. Rasmussen, G. and C. Rasmussen. Calmodulin-dependent protein kinase II is required for G1/S progression in HeLa cells. Biochem Cell Biol. 1995; 73: 201-7.

67. Heise, N., D. Palme, M. Misovic, S. Koka, J. Rudner, F. Lang, H.R. Salih, S.M. Huber, and G. Henke. Non-selective cation channel-mediated Ca2+-entry and activation of $\mathrm{Ca} 2+/$ calmodulin-dependent kinase II contribute to G2/M cell cycle arrest and survival of irradiated leukemia cells. Cell Physiol Biochem. 2010; 26: 597-608.

68. Vest, R.S., K.D. Davies, H. O'Leary, J.D. Port, and K.U. Bayer. Dual mechanism of a natural CaMKII inhibitor. Mol Biol Cell. 2007; 18: 5024-33.

69. Li, G., H. Hidaka, and C.B. Wollheim. Inhibition of voltagegated $\mathrm{Ca} 2+$ channels and insulin secretion in HIT cells by 
the $\mathrm{Ca} 2+/$ calmodulin-dependent protein kinase II inhibitor $\mathrm{KN}-62$ : comparison with antagonists of calmodulin and L-type Ca2+ channels. Mol Pharmacol. 1992; 42: 489-8.

70. Wang, T., Z. Liu, S. Guo, L. Wu, M. Li, J. Yang, R. Chen, H. Xu, S. Cai, H. Chen, W. Li, L. Wang, Z. Hu, et al. The tumor suppressive role of CAMK2N1 in castration-resistant prostate cancer. Oncotarget. 2014; 5: 3611-21.

71. Zhang, J., N. Li, J. Yu, W. Zhang, and X. Cao. Molecular cloning and characterization of a novel calcium/calmodulindependent protein kinase II inhibitor from human dendritic cells. Biochem Biophys Res Commun. 2001; 285: 229-34.

72. Ma, S., Y. Yang, C. Wang, N. Hui, L. Gu, H. Zhong, Z. Cai, Q. Wang, Q. Zhang, N. Li, and X. Cao. Endogenous human CaMKII inhibitory protein suppresses tumor growth by inducing cell cycle arrest and apoptosis through downregulation of the phosphatidylinositide 3-kinase/Akt/HDM2 pathway. J Biol Chem. 2009; 284: 24773-82.

73. Remsing Rix, L.L., U. Rix, J. Colinge, O. Hantschel, K.L. Bennett, T. Stranzl, A. Muller, C. Baumgartner, P. Valent, M. Augustin, J.H. Till, and G. Superti-Furga. Global target profile of the kinase inhibitor bosutinib in primary chronic myeloid leukemia cells. Leukemia. 2009; 23: 477-85.

74. Ma, C., K. Tang, Q. Liu, R. Zhu, and Z. Cao. Calmodulin as a potential target by which berberine induces cell cycle arrest in human hepatoma Bel7402 cells. Chem Biol Drug Des. 2013; 81: 775-83.

75. Gu, Y., T. Chen, Z. Meng, Y. Gan, X. Xu, G. Lou, H. Li, X. Gan, H. Zhou, J. Tang, G. Xu, L. Huang, X. Zhang, et al. CaMKII gamma, a critical regulator of CML stem/ progenitor cells, is a target of the natural product berbamine. Blood. 2012; 120: 4829-39.

76. Meng, Z., T. Li, X. Ma, X. Wang, C. Van Ness, Y. Gan, H. Zhou, J. Tang, G. Lou, Y. Wang, J. Wu, Y. Yen, R. Xu, et al. Berbamine inhibits the growth of liver cancer cells and cancer-initiating cells by targeting $\mathrm{Ca}(2)(+) /$ calmodulindependent protein kinase II. Mol Cancer Ther. 2013; 12: 2067-77. 